\title{
Risk Management Techniques: A Review and Study in Dealing with Coronavirus Disease of 2019 (COVID-19)
}

Teow Boon Keong ${ }^{1 *}$, Mohammed Khalifa Abdelsalam², Diara Md. Jadi², Ibrahim Mohammed Massoud Egdair ${ }^{3}$, Hussein-Elhakim Al Issa ${ }^{4}$, Omar Saad Saleh Abrika ${ }^{5}$

${ }^{1}$ School of Quantitative Sciences (SQS), College of Art and Sciences (CAS), Universiti Utara Malaysia (UUM), 06010 Sintok UUM, Kedah, Malaysia

${ }^{2}$ Department of Banking and Risk Management, School of Economics, Finance and Banking, University Utara Malaysia (UUM), 06010 Sintok UUM, Kedah, Malaysia

${ }^{3}$ Faculty of Economic and Accounting-Murzq, Sebha University, Sebha +218 S, Libya

${ }^{4}$ Independent Researcher, Queen Margaret University, Edinburgh EH21 6UU, United Kingdom

${ }^{5}$ Faculty of Pharmacy, Sebha University, Sebha +218 S, Libya

Corresponding Author Email: teow_boon_keong@sqs.uum.edu.my

https://doi.org/10.18280/ijsse.110501

Received: 17 June 2021

Accepted: 25 September 2021

\section{Keywords:}

COVID-19, direct losses, indirect losses, risk management techniques

\begin{abstract}
COVID-19 has been a global issue since its first case in November 2019. In March 2020, an increase in the statistics of this pandemic occurred worldwide. The direct exposures, such as human resource loss, and the indirect exposures, such as the systemic loss, have affected the individuals and the companies during the COVID-19 pandemic. The identified loss exposures could be measured using several methods to implement suitable actions for the management of the identified risks. However, it has been indicated from the analysis that a minimum of five months is required for it to be solved. Therefore, the losses due to COVID-19 could be managed using three different risk management techniques, including the risk control techniques, which do not involve money and risk financing techniques. Meanwhile, the alternative risk transfer under the aforementioned techniques involves the investment in capital. Notably, these techniques must be performed by three distinct parties: the individuals, companies, and the government.
\end{abstract}

\section{INTRODUCTION}

On the 3rd of February 2020, the public was faced with the outbreak of COVID-19 [1] due to the Novel Coronavirus (nCOV). Although the initial new Coronavirus was discovered in Wuhan, China, the origin of the virus was not known. However, more cases were found outside of the country at the end of February 2020, which brought attention to the public, especially the global organisations including the World Health Organisation (WHO) and World Bank or the International Bank for Development (WB). COVID-19 was then declared by the WHO as a pandemic on the 11th of March 2020 [2].

Theoretically, the pandemic is defined as an infectious disease, which firstly affected human's health individually and spread throughout the community or society due to the exposure of humans to pathogens from the animals. According to Jonas [3] the infected cases among 2.3 billion of individuals have been due to the virus originating from animals until 2013, while Chen et al. [4] added that COVID-19 is similar to the virus found in SARS and Middle East Respiratory Syndrome (MERS). Overall, all three diseases would lead to failure in the respiratory system.

Pandemic is no longer a new phenomenon for the public. The history of the pandemic has indicated that several necessary actions should be performed by the authorities to completely end the pandemic in the world. Furthermore, among the common pandemics in the previous era was the Third Cholera Pandemic in 1852, the Sixth Cholera Pandemic in 1910, the Flu Pandemic in 1918, and the AIDS Pandemic in 2012 [2], with animals being proven as the main keys of pandemics [3].

Before making suggestions to end this pandemic or reduce the probability of it and the outbreak of other types of pandemic, several factors should be considered. Specifically, the risks involved in COVID-19 should be determined and measured to manage the risks. The selection of COVID-19 as the main focus of this study is due to the potential losses from the pandemic, which could be observed by the researchers.

To review the management of the COVID-19 pandemic, the objectives of this study are as follows:

1. To study and measure the risks related to the COVID-19 pandemic based on other studies.

2. To analyse the period of the COVID-19 pandemic before it ends.

3. To study the techniques available to manage the risks based on the techniques reviewed from the literature.

4. To present the ideal risk management technique to manage these risks.

The scope of this study covers the risks related to COVID19 , which may be direct or indirect, including the fundamental techniques for risk management. Furthermore, the articles and journals selected from 2003 onwards were due to the reviews made regarding other pandemics. Notably, this study is important, especially for global organisations, such as WHO, and the national organisations including the Ministry of Health to make complete preparation for COVID-19. It is also crucial 
as a suggestion for the public to manage the risks related to COVID-19 and preparation of organisations for the possible split-over effect from the pandemic. Additionally, the public could gain advice from this paper regarding the preparation against COVID-19.

This section (Section 1) presented the introduction to the study. The risks identified in COVID-19 are highlighted in the next section. Section 3 will discuss the techniques used to manage the risks identified in Section 2. This is followed by Section 4, which will conclude the overall findings of this study.

\section{RISK IDENTIFICATION}

This section presents the risks related to COVID-19, which were identified from the literacy study regarding other diseases under the same category. The future trend of COVID19 was also determined to enhance the reliability of the risk management techniques, which are to be identified in the next section

\subsection{Review of study in the other similar diseases}

In the previous studies regarding similar diseases, such as SARS and MERS, a relatively high number of detected risks could still be referred to in the identification of risks related to COVID-19. The following section elaborated on the risks involved in some of the diseases and the management of the risks during this period.

\subsubsection{Cholera pandemic}

Staff $(2020)$ recorded a relatively high occurrence of the pandemic, as seen from the Third Cholera Pandemic in 1852 and the Sixth Cholera Pandemic in 1910 [2]. To manage the risks, the loss reduction technique was implemented to identify the causes after the Third Cholera Pandemic, considering that this technique could assist the authorities in minimising the death rates. This was followed by isolation and quarantine, which were the loss prevention techniques applied in risk management [5]. Subsequently, the combination of these techniques ended the cholera pandemic.

\subsubsection{Influenza (Flu) pandemic}

Occurred in 1918, the influenza (flu) pandemic mostly killed young and older people [2]. Provided that young individuals are the potential employees for a country, this pandemic was mentioned to lead to human resource loss exposure worldwide. At this point, isolation was performed as a loss prevention technique to reduce the number of individuals diagnosed with the flu.

The H1N1 outbreak emerged in 2009, with the highest mortality rate recorded among people with chronic diseases, pregnant women, and people with high Body Mass Index (BMI), as stated by $\mathrm{Yu}$ et al. [6]. As a result, the world was faced with human resources loss exposure. As a solution, loss prevention techniques were implemented, such as public gathering bans and quarantine [7], while loss reduction techniques, such as vaccination for seasonal flu (the main category of influenza) treatment, were performed simultaneously. The combination of loss prevention and loss reduction techniques reduced the new cases of the influenza pandemic.

\subsubsection{SARS/MERS}

According to Nanshan Chen et al., SARS and MERS have a strong association with COVID-19 [4]. Although the risks of the pandemic were only perceived to be related to human health issues, another issue raised regarding SARS and MERS led to a shock among the public. To illustrate, it was recorded in the World Bank that a significant drop occurred in the Gross Domestic Product of the countries that were affected by SARS and MERS after the outbreak of COVID-19 [8].

\subsection{Types of losses involved}

Two types of losses are involved in COVID-19, namely direct loss and indirect loss. Specifically, the direct loss mainly is related to the loss of lives, while the indirect loss is related to the subsequent loss related to economics.

\subsubsection{Direct loss}

The direct loss from COVID-19 is directly related to the loss of human lives, which brings impacts to a company or an individual. The following subsections present further details regarding the loss.

Direct loss exposure to the companies. Human resource loss exposure is the main risk of COVID-19 faced by the company. According to Chen et al. [4], COVID-19 is highly risky especially to individuals with chronic diseases, such as hypertension, diabetes, and coronary heart diseases [9], including individuals who lead unhealthy life habits. Patients with coronary heart disease would encounter more severe pneumonia compared to those without the disease. Furthermore, according to the primary research performed on 99 premier patients of COVID-19 in Wuhan, COVID-19 was found to have a more severe effect on males compared to females [4]. Provided that the males are the main manpower of the industry, the impact of this pandemic on the males led to human resource loss exposure to organisations worldwide.

A more critical case of COVID-19 was illustrated by World Bank in "East Asia and Pacific in the time of COVID-19", which stated that nCOV had a high transmissibility rate. This finding was supported by the Basic Reproductive Ratio of 4.5, with zero herd immunity detected [8]. The transmissibility rate of COVID-19 was higher compared to MERS and SARS, in which the prepandemic SARS-COV only presented a Basic Reproductive Ratio of 0.8 . This situation raised concerns among the public [10], which also proved that the human resource loss exposure would be a major direct risk faced by the company as an impact of the pandemic.

Direct loss exposure to the individuals. Two types of main pandemic risks affect humans, namely, spark risk and spread risk. Specifically, Nita et al. [11] highlighted that spark risk is related to the severity of the particular pandemic to the individual and is highly indicated by the number of deaths to emerge from COVID-19. Overall, the increase in the death rate implies a higher spark risk of COVID-19. The number of new daily death cases until the 3rd of April 2020 was approximately 6000 [12], which was considered high. Meanwhile, the spark risk is related to the severity of the situation suffered by an individual due to COVID-19. Notably, death is the most possible loss in this case.

According to Nita et al. [11], the spread risk is related to the frequency of the pandemic to an individual. This risk is reflected by the total new daily cases, which will occur in 
COVID-19, in which a higher number of new daily cases indicates a higher frequency of COVID-19 spread risk. Until the 3rd of April 2020, approximately 100,000 cases daily new cases were recorded [12], which were considered frequent. For an individual, the spread risk is related to the frequency of the impact of COVID-19 on an individual within a particular time frame, which may be up to a year. The possible highest loss would occur when natural immunity is present within the individuals who are infected by COVID-19. Notably, the finding of this study was in line with the finding by Nita et al. [11], considering that the same theory, which was proposed by Liao et al. [13], indicated that the frequency and the severity of risk involved in the infectious disease outbreak must be studied thoroughly for the risk management.

\subsubsection{Indirect loss}

Apart from the indirect loss, several indirect losses from the COVID-19 pandemic were also present, which influenced two categories, namely companies and individuals.

Indirect loss exposure to companies. The indirect exposures to companies can be due to the strategies and techniques used to manage the COVID-19 pandemic, which will be discussed in Section 3. Essentially, business income loss exposure is one of the risks faced by the companies upon the impact of COVID-19 [8]. As proposed by the World Bank, the loss exposure is due to the supply and demand shock from the techniques used by the government to control the transmission of COVID-19. It was also stated that the shock is due to the preventive behaviour of the suppliers, which is the fear of the drop in sales due to the reduced income level among the residents. Meanwhile, the preventive behaviour of the consumers is the fear of the virus on the goods they consume and the transmission control policies by the government, which limit the mobility of the goods and services. This notion was supported by Staff [2], who stated that the mandatory stayat-home measures would reduce business income. All of the aforementioned situations have indicated that companies may experience a severe income drop during and after the pandemic.

Apart from the business income loss exposure, systemic loss exposure (or systemic risk) is another loss exposure faced by all the companies during the COVID-19 pandemic [8]. According to the World Bank (2020), the systemic risk is due to the recession, which may occur due to the drop in the Gross Domestic Product (GDP). Before the COVID-19 pandemic, the International Monetary Fund (IMF) projected the GDP values from 2020 to 2024 (refer to the attached Excel file) with a $95 \%$ confidence rate.

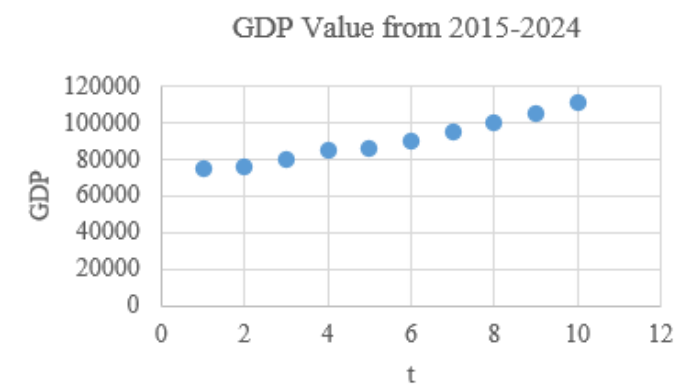

Figure 1. GDP values by the IMF (2015-2024) (Data source: IMF, 2019)
Figure 1 above shows the GDP values from 2015 to 2019 and the initial projected GDP values from 2020 to 2024, where $t=1$ is marked at 2015. It could be seen from the figure that the projected GDP increases with the increasing confidence rate.

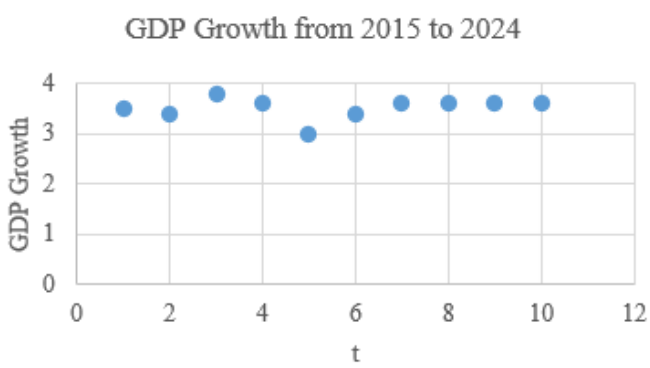

Figure 2. GDP growth by IMF from 2015 to 2024 (Data source: IMF, 2019)

Figure 2 above shows the real GDP growth from 2015 to 2019 and the initially projected GDP growth from 2020 to 2024 by IMF in 2019. Overall, Figure 1 and Figure 2 illustrate the optimistic projected economic situation by the IMF before the pandemic.

The loss exposure for the companies after the outbreak of COVID-19 due to the optimistic situation is a concerning situation. According to Zandi et al. [1], the pandemic would reduce the initially projected GDP growth from $3.4 \%$ to $2.5 \%$ as projected initially. This systemic risk would lead to various small and medium companies into bankruptcy as a result of significant economic loss [3].

In the case of multinational companies (MNCs), another inevitable loss exposure is the foreign exchange loss exposure. As proposed by the World Bank [8], the decrease in the frequency of travelling between the countries due to the transmission control would impact the exchange rate between the countries in the world. As a result, higher translation exposure would result in the economic and transaction exposures, which are faced by MNCs throughout the pandemic. The widespread of COVID-19 on the global scale causes fear of unnecessary travel among people, which subsequently leads to the connection between the import and export trades, including international business trades.

The World Bank projected two scenarios for the MNCs, namely 1) the possible maximum loss of severe slowdown of international trade despite the fast recovery and 2) the possible maximum loss of slowdown of international trade, which is less severe despite the slow recovery.

Indirect loss exposures to individuals. The indirect loss exposure among the individuals is mainly indicated by the changes in the individuals' consumption behaviour and income level. According to Yue et al. [14], the indirect loss exposure among the individuals is the inconvenience loss exposure due to public panic and the trauma experienced by people upon travelling after the pandemic period. As a result of the continuous inferiority of COVID-19 vaccine, the downturn of the vaccine consumption has taken place among the public. The limitation of the daily consumption is a loss since the individuals enjoy the life less due to the panic. According to the World Bank, the closure of schools leads to inconvenience loss exposure to the individuals, especially students due to their incapability to receive proper education compared to their capability before the pandemic. 
Similarly, according to the World Bank, individuals will possibly face the purchasing power decline loss exposure. This is due to the drop in the income level and the increase in the goods price results from the decrease in supply [14] and the increased transaction cost [8]. Meanwhile, the shortage of beds and medical equipment leads to inadequate purchase power among the individuals in the healthcare sector, which may lead to health-related issues.

\subsection{Projection of the COVID-19 pandemic}

The projection of the period of COVID-19 is highly important in determining the suitable techniques to manage the loss exposure, which was identified in the previous subsection. This projection is also based on the new cases and death reported daily until the 4th of April 2020, which was the date when this study took place.

\section{Daily New Cases}

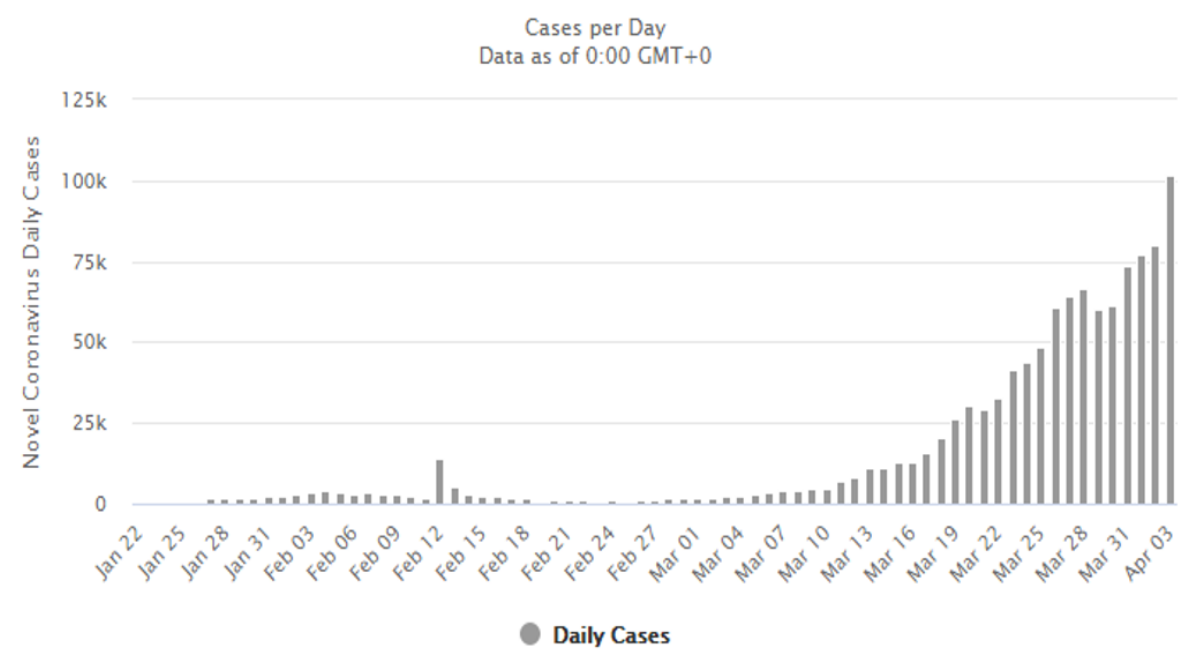

Figure 3. New Daily COVID-19 Cases by the 4th of April 2020 (Figure source: Worldometer, 2020)

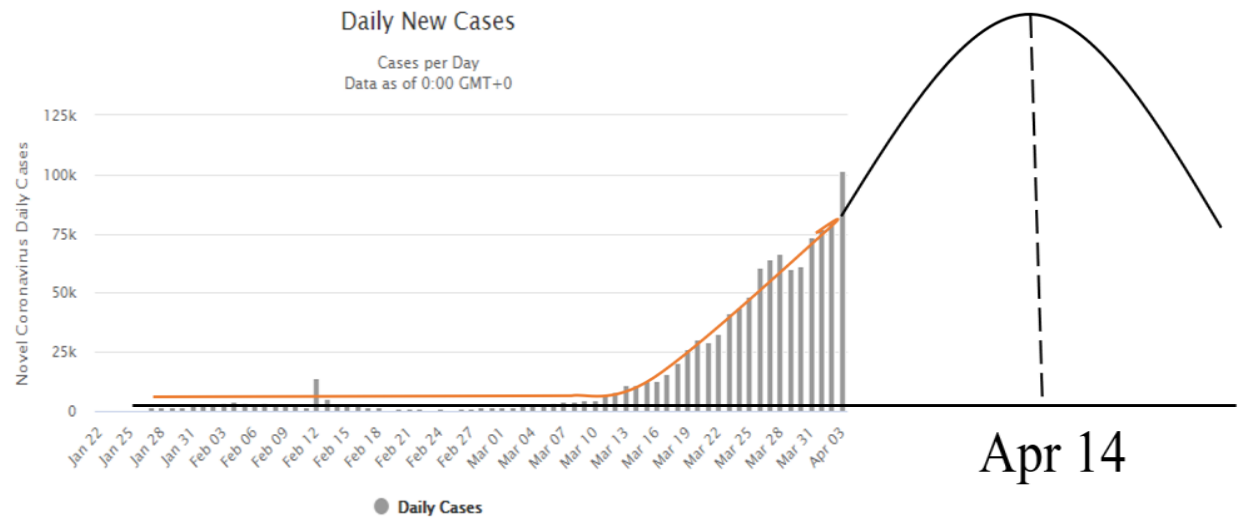

Figure 4. Projected New Daily COVID-19 Cases after the 4th of April 2020

\section{Daily Deaths}

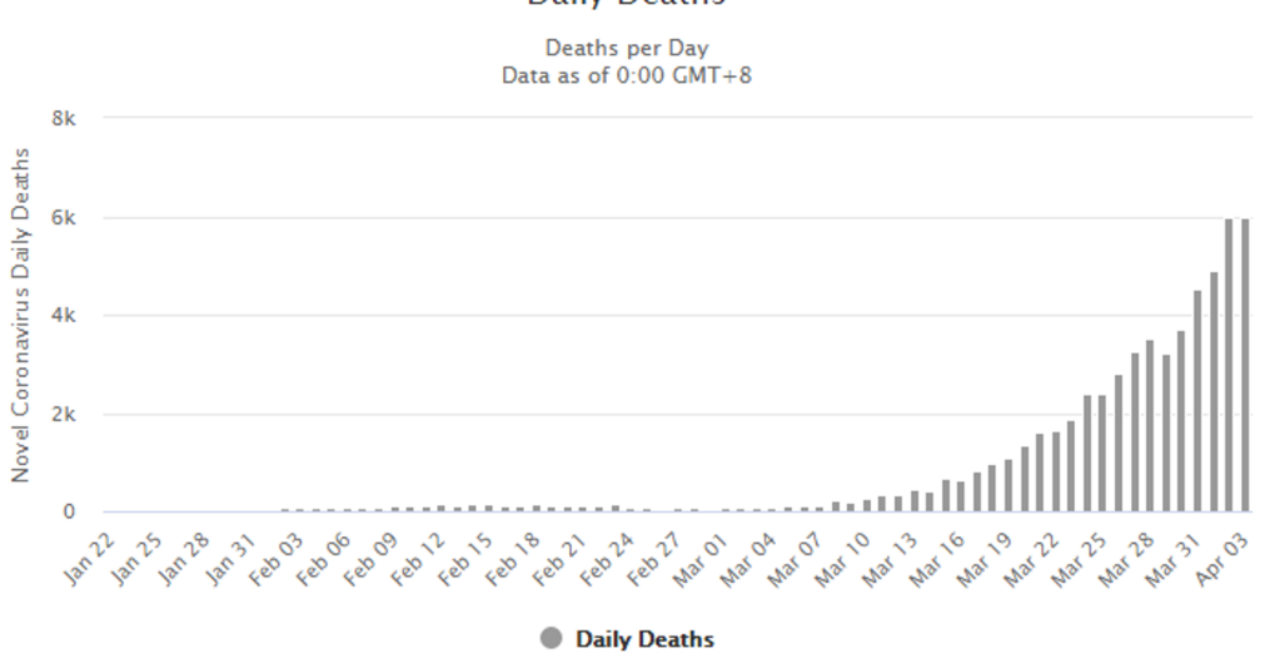

Figure 5. New Daily COVID-19 Death Cases by the 4th of April 2020 (Data source: Worldometer, 2020) 


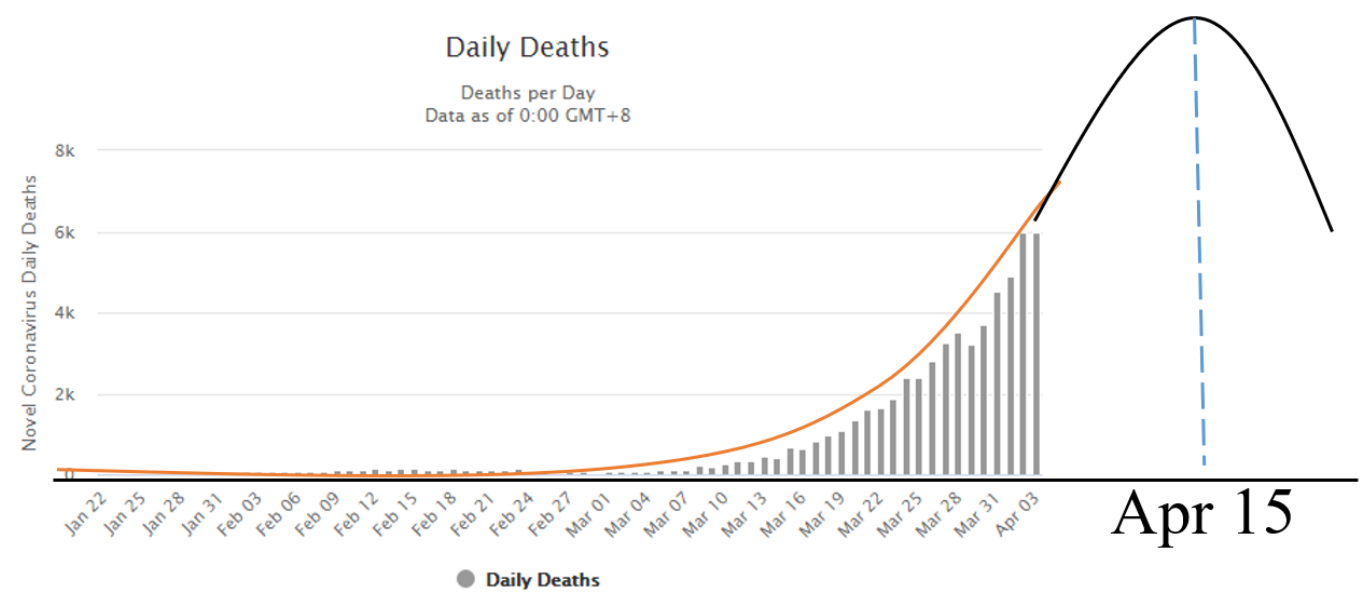

Figure 6. Projected Daily COVID-19 Death Cases after 4th of April 2020

It could be seen from Figure 3 that the peak of the daily new cases did not take place on the 4th of April 2020. However, it was predicted that the daily new cases would continue to increase until the peak is reached.

The new daily cases of death were another focus among researchers in the pandemic management field. Figure 4 summarises the prediction of the new daily cases through the naturally built curve. As a normal distribution was suggested, every phenomenon, which occurs naturally, was predicted to follow the bell-shaped curve [13]. It was also expected that the new daily cases would reach a peak around the 14th of April 2020 , as indicated through the orange line. While the orange line represents the curve of ready daily new cases, the black line represents the curve of projected daily new cases.

It can be seen from Figure 5 above that the new daily COVID-19 death cases did not reach the peak on the 4th of April 2020. However, it was predicted that the cases would continue to increase until the following point is reached.

The bell-shaped curve in Figure 6 indicates the new daily death cases, which specifically predict that these cases would reach a peak on the 15th of April 2020. Overall, it could be seen from Figure 4 and Figure 6 that the cases of COVID-19 would only reach a peak in the mid of April 2020. Therefore, the earliest predicted date for this pandemic to end was the $1 \mathrm{st}$ of July 2020.

Table 1. Prediction of days for the whole COVID-19 pandemic

\begin{tabular}{ccc}
\hline Date & Stage & Number of Days \\
\hline $\begin{array}{c}30^{\text {nd }} \text { of January } \\
2020-15^{\text {th }} \text { of } \\
\text { April } 2020\end{array}$ & $\begin{array}{c}\text { The beginning } \\
\text { of COVID-19 }\end{array}$ & $\begin{array}{c}\text { Approximately 75 days } \\
(2 \text { months and a half })\end{array}$ \\
$15^{\text {th }}$ of April 2020 & $\begin{array}{c}\text { The peak of } \\
\text { COVID-19 }\end{array}$ \\
$15^{\text {th }}$ of April 2020 & The ending of & $\begin{array}{c}\text { Approximately 75 days } \\
\text { (2 months and a half) }\end{array}$ \\
$-1^{\text {st }}$ of July 2020 & COVID-19 & Approximately 150 days \\
Total & - & (5 month) \\
\hline *With the assumption that no significant change occurred in the slope of
\end{tabular}
the curve after the 4th of April 2020

Table 1 above presents a brief analysis of the dates of the records of COVID-19. Provided that the naturally bell-shaped curve has a symmetric property, the beginning and the ending phase of the pandemic would take place on the same day, with a prediction that the earliest date for the pandemic to end was the 1st of July 2020. Following the indication that loss exposure would be faced by the companies and the individuals for a minimum of five months excluding the period after the pandemic, risk management techniques must be applied to combat the risks of COVID-19.

\subsection{Risk measurement}

After the risk identification process, the measurement of the risks related to the COVID-19 pandemic is crucial. According to the discussion in the previous section, the risks of this pandemic on both individuals and companies must be measured within a minimum of five months of the pandemic period. Although the measurement of the risks is not possible due to several constraints, the results of the available studies regarding COVID-19 and similar pandemics to it are introduced.

\subsubsection{Basic reproduction number of pathogens infection, $R_{0}$}

This reproduction number of pathogens infection is the most basic risk measurement technique to estimate the risks involved in the pandemic. According to Breban et al. [10], this technique is implemented to estimate the inter-transmission rate of MERS and identify the risks related to COVID-19. It is noteworthy that $R_{0}$ should not be equal to 1 . Moreover, the Bayesian analysis is used to analyse the pandemic risk related to the basic reproduction number.

\subsubsection{Exceedance probability (EP)}

The previously stated Bayesian analysis is related to the EP, which is another method used to assess the pandemic risk. According to Nita et al. [11], EP is used to measure the possibility and severity of the possible pandemic risk. Provided that the EP is calculated based on the dependency of one event on another event, it is used to calculate the probability of a person to be infected by a COVID-19 patient.

\subsubsection{Global health security index (GHS Index)}

GHS Index is the method used to measure the capabilities of COVID-19 [15]. Compared to previous methods of measuring the pandemic risk, this method is used to measure the ability of the country to manage the pandemic. According to McAleer (2020), the rate of preparedness of the world for COVID-19 amounted to less than 50, which was weak, despite its benefit as a countermeasure against COVID-19 in the future with the implementation of strategies [8]. 
2.4.4 Concept of differentiation and simple algebra

Differentiation and simple algebra are used to analyse the rate of COVID-19 transmission. It was also stated by Tang et al. [16] that the method of differentiation could be used to estimate the maximum and the minimum rate of COVID-19 transmission. Notably, the rate could be determined using simple algebra. Following is a simple property attached in the estimation of the maximum and minimum rate of transmission for effective implementation of the available techniques.

$$
\frac{\partial R}{\partial t}=0
$$

where,

$R$ : Function of transmission of 2019-nCOV;

$t$ : Time taken for the transmission of 2019-nCOV from person to person.

\subsubsection{Mathematical models}

The final stage of risk measurement involved in COVID-19 is the development of mathematical models. In this case, two models are involved, namely the time-dependent dynamic model [16] and the multiple regression model [13]. According to Tang et al. (2020), the time-dependent dynamic model was used to estimate the rate of COVID-19 transmission among human beings. The time variable is used as the independent variable, while the rate of transmission is used as the dependent variable. The general model is as follows:

$$
R(t)=\sum_{i=0}^{n} a_{i} t^{i}
$$

where,

$R$ : The rate of transmission of 2019-nCOV at time $t$;

$n$ : The highest power of the function $R$ (follow the trend).

In the earlier stage, multiple regression was proposed by Liao et al. [13] to estimate the rate of transmission of a pandemic virus using the factors determined from the study. Compared to the time-dependent dynamic model, which considers the components of time series, the multiple regression only takes the factors identified from the environment and experience into account.

$$
R(x)=\sum_{i=0}^{n} a_{i} x_{i}
$$

where,

$R$ : The rate of transmission of 2019-nCOV;

$x$ : The factors affecting the rate of transmission of 2019 $\mathrm{nCOV}$;

$n$ : The highest number of factors affecting $R$.

\subsubsection{Risks measured}

Based on all the methods stated in this subsection, the COVID-19 was found to comprise the following features:

1. The $R_{0}$ of COVID- 19 is 4.5 [8].

2. The GHS Index of the world against the COVID-19 is 40.2 out of 100 [15].

3. The recovery of the pandemic in China required 60 days [16].

\section{RISK MANAGEMENT TECHNIQUES SELECTION}

This section discusses the selected risk management techniques for the management of COVID-19 with a reference to previous studies regarding the same type of disease. Various risk management techniques were selected by various parties to address COVID-19, namely risk control techniques, risk financing techniques, and alternative risk transfer techniques.

\subsection{Risk control}

Provided that the actions involved in risk control techniques are physical and mental actions without any financial involvement, the investment of capital is not performed. It was found in history that the combination of loss prevention technique and loss reduction technique was the most efficient technique in the management of pandemic risk [2]. However, other risk control techniques were possibly applied to manage the economic risk from the pandemic.

\subsubsection{Loss avoidance}

Loss avoidance is the most convenient and least costconsuming technique as it only requires the residents to prevent themselves from the COVID-19 pandemic. Furthermore, this technique is suitable to be applied among children and older individuals as they belong to the group with the highest mortality rate [9] and the weakest immunity against COVID-19. It was suggested by the World Bank that this technique is also supported by the closure of schools and the travel ban. These initiatives would prevent older individuals from exposure to the pandemic. Moreover, although the loss avoidance technique was proposed by the Staff [2] by applying the mandatory stay-at-home measures, it was not deemed as realistic due to its excessively strict limitation. Being the main disadvantage of this technique, it restricts economic activities and disrupts the prevention of several risks, such as business income loss exposure.

\subsubsection{Loss prevention}

Provided that the implementation of loss avoidance is not realistic, this technique is introduced to reduce the frequency of loss, particularly the spread of the pandemic risk [11]. According to Staff [2], loss prevention is among the most efficient techniques in the ideal combination of risk control, which has also been supported by several previous findings. According to the Imperial College COVID-19 Response Team, suppression or social distancing is among the suggested loss prevention techniques. Furthermore, country transmission and control policies are applied in almost all countries as loss prevention techniques [8].

The government of Hong Kong enforces the loss prevention technique by urging medical personnel to practice airborne precautions, hand hygiene, and the use of protective equipment [17]. A waveform capnography monitoring device is used on the pattern of ventilation to reduce the number of people infected by COVID-19. According to Cheung et al. [17], rapid sequence induction in emergency incubation is one of the loss prevention techniques to manage the risks related to COVID-19, especially the pandemic risk. However, provided that the preparedness of the world for COVID-19 was found to be weak [15], it was suggested that social awareness should be the most prioritised loss prevention technique, as proposed by World Health Organisation (2010) 
and Nita et al. [11]. This approach would enhance the public's preparedness for the pandemic.

\subsubsection{Loss reduction}

Apart from loss prevention, this technique is among the most efficient techniques for managing the pandemic risk and reducing its severity [11]. However, loss reduction techniques are applied in wider aspects compared to the loss prevention techniques as per the suggestion in the previous subsection. Notably, the loss reduction techniques reduced the severity of loss exposure related to individuals and the companies, distinguishing them from the loss prevention techniques, which are not required to reduce the frequency of loss exposure to the companies. Besides, all companies are affected by systemic risk.

Loss reduction techniques in reducing the severity of loss related to individuals. Loss reduction techniques are important to reduce the severity of COVID-19 infection and the loss of income from it. According to Yue et al. [14], the development of a vaccine is among the most important loss reduction techniques performed by the research institute to achieve this objective. The use of the vaccine was suggested by the Imperial College COVID-19 Response Team [8], which was also supported by an earlier study as it highlighted that vaccines are the ideal treatments for pandemics [7]. In the case of the medical personnel, the medical techniques should be improved to perform professional management of the people infected by COVID-19 [14].

The fiscal and monetary policies imposed by several countries could reduce the loss of income due to COVID-19 by increasing governmental expenditures and reducing taxes [8]. A similar study illustrated that economic recovery policies are also effective in reducing the severity of the income loss as the citizens are provided with funds, as illustrated in the poverty policies. In this study, it was suggested that online platforms, such as online banking and online doctor-on-call, could be used as a loss reduction technique for infected individuals and loss of income.

Loss reduction techniques in reducing the severity of loss related to companies. Upon the closing of all companies, some loss reduction techniques have been introduced to reduce the loss experienced by the companies. The previous studies supported the economic recovery policies as the methods to solve the loss from pandemics by assisting the individuals involved in the loss and providing funds to the companies as subsidies. Additionally, survival is the main post-loss objective of the companies during this pandemic, as suggested by the World Bank. The fiscal and monetary policies imposed by several countries could also reduce the severity of loss of income experienced by companies by increasing government expenditures and reducing the imposed company income taxes [8].

\subsubsection{Other risk control techniques}

Besides the combination of loss prevention and loss reduction techniques, other risk control techniques are important to reduce the severity and frequency of the risks related to the COVID-19 pandemic, especially among the companies. Specifically, loss separation techniques could be implemented to distribute subsidiaries and involve the closing of companies in areas exposed to high risk of COVID-19 and the opening of areas with low risk. Notably, these techniques are only applicable to one single country. However, a thorough closure of the economic activities and the transmission control policies [8] appears to be challenging for the companies.

Although domestic companies have been suggested to apply the loss reduction techniques, the multinational companies (MNCs) are not adequate for the implementation of these techniques. Apart from the aforementioned two techniques, it was suggested in other studies that loss diversification is another risk control technique, which needs to be applied by the MNCs. This implementation is important especially for the MNCs, which open subsidiaries in China and the United States of America (USA). As suggested by Zandi et al. [1], these two countries have suffered from serious global economic threats due to COVID-19.

According to World Bank (2020), the loss diversification during the COVID-19 pandemic could be performed in two ways, namely the economic sectors and regional diversifications. Specifically, the economics sectors diversification requires the reduction of business by MNCs and investments in the non-medical sectors, especially the travel sectors [8] However, the investments in the medical sectors should be increased, especially the policy of the insurance and the financial sectors. Large data analysis could also be performed by the companies on the sectors with a potential in the COVID-19 pandemic and the low-risk regions, which are recognised by the scientific research institutions [14].

\subsection{Risk financing}

Besides the risk control techniques, the risk financing techniques, which involve funds, also need to be applied to manage the risks related to the COVID-19 pandemic. In this case, investment of capital is performed, while the risk financing, retention, commercial insurance, and non-insurance risk transfer could be implemented.

\subsubsection{Retention}

This technique is applied by two parties in the country to manage the minor losses related to the COVID-19 pandemic, namely the companies and government. However, the retention technique can be used only in the short term. It was suggested by World Bank that retention should be performed by the companies to grant benefits to employees upon the loss of business income and the increase in material price in the future. To illustrate, despite the closure of companies during the pandemic, the employees still should be paid by the companies as enforced by the government. Moreover, the closing of the business operation would increase the material price due to the shortage of stocks [8]. However, this technique could only be implemented for a temporary period. A similar technique to retention was proposed by Yue et al. [14]. This proposal suggested the setting of funds by the government administration, which is performed to assist the corporates in the distribution of wages to the workers during the pandemic. The production of medical supplies, such as face masks and breathing supporting machines, also requires funds from the governmental administration.

\subsubsection{Commercial insurance}

Compared to retention, which is limited by the resources of the companies and the government, commercial insurance is another risk financing technique suitable for a long-term pandemic. Two types of insurance could be applied to manage 
the risks related to COVID-19, namely life insurance and nonlife insurance.

To be specific, life insurance is used mainly to combat health-related risks for individuals. According to Dubey [18], the beneficiaries of the existing policyholders will obtain death benefits from the policyholders' death due to the COVID-19 outbreak. For the individuals who attempt to purchase new life insurance policies, the insurer may choose to reject the policy when the policyholder is diagnosed to be COVID-19 positive. However, this option is possible only when an insurance policy is still in process. If a new attempt of buying a policy will be made, the insured must not be infected with COVID19 and should obtain the information regarding the conditions for the policy purchase. Nevertheless, no issue would emerge from life insurance as long as the COVID-19 pandemic is not perceived as too severe [18].

In the case of non-life insurance, which is mainly used to combat the risks related to COVID-19 in organisations, the processes in this action are challenging. To illustrate, provided that the premiums for term insurance could increase, commercial insurance under risk financing is not an ideal strategy to transfer the risk. Additionally, the premium will not be significant in holding an insurance policy if COVID-19 is considered a critical illness [18].

\subsubsection{Non-insurance transfer}

Provided that commercial insurance appears to be an irrelevant approach for the companies to manage the risks related to the pandemic, the non-insurance transfer is introduced. There is a possibility for the transfer to be achieved as it involves more than one company.

Incorporation is a major technique, as proposed by the World Bank in 2020. This technique aims to motivate the merging of small companies to gain financial support from each other [8]. This action would reduce the financial burden of one single company, which needs to distribute wages and make fixed expenses despite the closing of the companies. The earlier incorporation was introduced by Jonas in 2013, which involved the merging of small companies and collaboration between the countries. In this case, the countries could collaborate by sharing information and medical supplies [3] in the world's effort to collectively combat COVID-19. Another suggested non-insurance transfer is hedging [8], which suggests future investment and options not only for the affected to reduce loss, but also to speculate in the potential areas.

\subsection{Alternative risk transfer (ART)}

Alternative Risk Transfer (ART) is among the non- traditional risk financing techniques, which are developed through modern risk management personnel and involve the investment of capital. Besides, among the suggested alternative risk transfer techniques are catastrophe securities and infinite loss contracts.

\subsubsection{Catastrophe securities}

According to Kampa [19], a type of security is suggested to manage the catastrophe loss similar to the one in the COVID19 pandemic. These securities are mainly related to non-life insurance linked sectors. The uninsurable risk in the COVID19 pandemic could be hedged using the catastrophe bonds, with one of the catastrophe securities being regarded as critical In this case, catastrophe bonds could hedge risks, which result in a significant loss. Catastrophe bonds only carry low risk or nearly no credit risk as they are managed by a Special Purpose Vehicle (SPV). According to Kampa [19], other catastrophe securities include industry loss warranties, which frequently set loss for the substantial loss (the payout will be made when the loss is touched). Catastrophe derivatives are involved, in which the payout is based on a single event loss according to the industry loss index, including sidecars where capital is provided to the insurer (increased capacity for the insurer to pay the insured), and contingent capital where a loan agreement is made for the insurer to increase the payment to the insured. Provided that the rating of catastrophe bonds is based on the probability of default during the catastrophe events, the risk of the collapse of the market is reduced.

\subsubsection{Infinite loss contracts}

This ART technique was proposed in this study with a reference to a suggestion by Jonas in 2013 that the financing framework should be created by the World Bank to distribute the funds into the market, increase the price of the shares in the market, and refresh the market [3]. However, the suggestion could be improved through the investment of the initial amount by each country, as proposed in the World Bank. When the losses due to the COVID-19 pandemic exceed the amount of investment, the World Bank would compensate for the losses until the specified limit is reached. The remaining losses would be compensated by the related country, which is followed by payment to the World Bank as instalments.

\subsection{Summary of most appropriate risk management techniques suggested}

This subsection briefly specifies different risk management techniques into three parties as summarized in Table 2, namely the individuals, companies, and the government $[20,21]$.

Table 2. The suggested risk management techniques

\begin{tabular}{cccc}
\hline $\begin{array}{c}\text { Risk management } \\
\text { techniques }\end{array}$ & Individuals & Companies & Government \\
\hline Risk control & $\begin{array}{c}\text { Loss prevention: Raising social awareness } \\
\text { against COVID-19 } \\
\text { Loss reduction: Online platforms, such as } \\
\text { online banking and the on-call doctor to } \\
\text { recover economics }\end{array}$ & $\begin{array}{c}\text { Loss reduction: Economy recovery policies } \\
\text { Risk financing }\end{array}$ & $\begin{array}{c}\text { Commersification: Economic sectors and } \\
\text { regional diversifications }\end{array}$ \\
ART & - & $\begin{array}{c}\text { Retention: Payment of benefits to the employees, } \\
\text { loss of business income, and the increased material } \\
\text { price in the future }\end{array}$ & $\begin{array}{c}\text { Retention: } \\
\text { Setting funds }\end{array}$ \\
\hline
\end{tabular}




\section{CONCLUSION AND RECOMMENDATION}

This section will conclude the overall findings and results of this study, which are followed by recommendations and several limitations.

\subsection{Conclusion}

In conclusion, there are numerous direct and indirect risks related to COVID-19 pandemic. Generally, the risks include loss exposures to the individuals and the companies. The summary of the direct and indirect risks is presented in the Table 3.

These risks should be identified and measured for the implementation of diverse risk management techniques.
Notably, these techniques would be crucial within two and a half months from April, considering that the actual period for the COVID-19 to remain in Malaysia may be reduced with effective risk management.

Through the study, the three parties i.e. the individuals, the companies and the government respectively could employ the risk management techniques to overcome the direct and indirect losses, and fulfil the pre-lost and post-lost objectives. For example, the companies can support the actions by the government by applying the subsidies especially the wage subsidies. Through this, the company can reduce the human resources loss exposures, the individuals can reduce the purchasing power loss exposure, and the country can reduce the economic downturn.

Table 3. Summary of the risks

\begin{tabular}{c|c|c|c}
\hline \multicolumn{2}{|c|}{ Direct Risks } & \multicolumn{2}{c}{ Indirect Risks } \\
\hline Companies & Individuals & Companies & Individuals \\
\hline Human resources loss & Pandemic risk (Spark risk and spread & Business income loss & Inconvenience loss exposure [14] \\
exposures [4] & risk) [11] & exposure [8] & Purchasing power loss exposure \\
& & Foreign exchange loss & \\
& & exposure [8] & \\
\hline
\end{tabular}

\subsection{Recommendation and limitation}

Based on the changes of the model and COVID-19 variation characteristics, it is recommended that a future study makes a proper implementation of the quantitative aspect of the risk management techniques to create a numerical justification about the most appropriate risk management techniques with less or no subjectivity. This is for stronger support basis. As shown in Eq. (3), multiple regression model calculates the risks related to COVID-19, while the respective techniques are highly encouraged for researchers to achieve more unbiased outcome.

In the case of real-life COVID-19 management application, it is recommended that the public cooperates with the authorities, especially the mandatory stay-at-home measures and the travel ban policies to reduce the loss exposures from the pandemic. The companies and the government are also responsible for the welfare of the employees and the citizens.

\section{ACKNOWLEDGMENT}

Hereby the researchers acknowledge that this publication is genuine by the authors. If any contents in this article are taken from the other sources, the credit had been given to the respective authors as recognition to their works.

\section{REFERENCES}

[1] Zandi, M., deRitis, C., Sweet, R., Cochrane, S., Ell, K., $\mathrm{Xu}, \mathrm{X}$. (2020). Coronavirus: The global economic threat. Moody's Analytics, USA.

[2] Staff. (2020). Outbreak: 10 of the Worst Pandemics in History. Retrieved from MPH Online: https://www.mphonline.org/worst-pandemics-inhistory/.

[3] Jonas, O. (2013). Pandemic Risk. The World
Development Report.

[4] Chen, N., Zhou, M., Dong, X., Qu, J., Gong, F., Han, Y., Qiu, Y., Wang, J., Liu, Y., Wei, Y., Xia, J., Yu, T., Zhang, X., Zhang, L. (2020). Epidemiological and clinical characteristics of 99 cases of 2019 novel coronavirus pneumonia in Wuhan, China: A descriptive study. The Lancet, 395(10223): 507-513. https://doi.org/10.1016/S0140-6736(20)30211-7

[5] World Health Organization. (2010). The World's Emergency Room. In Outbreak (pp. 121-138). World Health Organization.

[6] Yu, H., Feng, Z., Uyeki, T.M., et al. (2011). Risk factors for severe illness with 2009 pandemic influenza A (H1N1) virus infection in China. Clinical Infectious Diseases, 52(4): 457-465. https://doi.org/10.1093/cid/ciq144

[7] Monto, A.S. (2009). The risk of seasonal and pandemic influenza: prospects for control. Clinical Infectious Diseases, $\quad 48(\mathrm{~S} 1)$ : $\quad$ S20-S25. https://doi.org/10.1086/591853

[8] World Bank. (2020). East Asia and Pacific in the Time of COVID-19. Washington: World Bank Group.

[9] Zhou, F., Yu, T., Du, R., et al. (2020). Clinical course and risk factors for mortality of adult inpatients with COVID19 in Wuhan, China: A retrospective cohort study. The Lancet, 395(10229): https://doi.org/10.1016/S0140-6736(20)30566-3

[10] Breban, R., Riou, J., Fontanet, A. (2013). Interhuman transmissibility of Middle East respiratory syndrome coronavirus: estimation of pandemic risk. The Lancet, 382(9893): 694-699. https://doi.org/10.1016/S01406736(13)61492-0

[11] Nita, M., Ben, O., Mark, G., Prime, M., Edward, R., Nathan, W. (2017). Chapter 17 Pandemics: Risks, Impacts, and Mitigation. In G. H. Jamison DT, Disease Control Priorities: Improving Health and Reducing Poverty. 3rd edition (pp. 1596-1633). Washington: The International Bank for Reconstruction and Development. 
[12] World Health Organization. (2020). COVID-19 Coronavirus Pandemic Statistics. Retrieved from Worldometer:

https://www.worldometers.info/coronavirus/coronavirus -cases/.

[13] Liao, Y., Xu, B., Wang, J., Liu, X. (2017). A new method for assessing the risk of infectious disease outbreak. Scientific Reports, $\quad 7(1)$ : 40084 https://doi.org/10.1038/srep40084

[14] Yue, X.G., Shao, X.F., Li, R.Y.M., Crabbe, M.J.C., Mi, L., Hu, S., Baker, J.S., Liang, G. (2020). Risk management analysis for novel Coronavirus in Wuhan, China. Journal of Risk and Financial Management, 13(2): 22. https://doi.org/10.3390/jrfm13020022

[15] McAleer, M. (2020). Prevention is better than the cure: Risk management of COVID-19. Journal of Risk and Financial Management, 13(3): 46 https://doi.org/10.3390/jrfm13030046

[16] Tang, B., Bragazzi, N.L., Li, Q., Tang, S., Xiao, Y., Wu, J. (2020). An updated estimation of the risk of transmission of the novel coronavirus (2019-nCov). Infectious Disease Modelling, 5: 248-255. https://doi.org/10.1016/j.idm.2020.02.001

[17] Cheung, J.C.H., Ho, L.T., Cheng, J.V., Cham, E.Y.K., Lam, K.N. (2020). Staff safety during emergency airway management for COVID-19 in Hong Kong. The Lancet Respiratory Medicine, $\quad$ 8(4): e19. https://doi.org/10.1016/S2213-2600(20)30084-9

[18] Dubey, N. (2020). Are deaths due to coronavirus covered by life insurance policies? Retrieved from Economics Times:

https://economictimes.indiatimes.com/wealth/insure/life -insurance/are-deaths-due-to-coronavirus-covered-bylife-insurance-policies/articleshow/74687234.cms

[19] Kampa, C. (2010). Alternative Risk Transfer: The Convergence of The Insurance and Capital Markets Part II. Research ISI, 1-8.

[20] Rejda, G.E., McNamara, M.J. (2017). Principles of Risk Management and Insurance. 13th ed. Essex: Pearson Education Limited.

[21] Lim, C.C. (2011). Risk Management. Petaling Jaya: Pearson Malaysia Sdn Bhd.

\section{NOMENCLATURE}

$R_{0}$ $\mathrm{EP}$

Basic reproductive number Exceedence probability Alternative Risk Transfer 